\title{
Can Biomimetic Zinc Compounds Assist a $(3+2)$ Cycloaddition Reaction? A Theoretical Perspective
}

\author{
Esra Bozkurt, ${ }^{\dagger}$ Thereza A. Soares, ${ }^{\dagger, \ddagger}$ and Ursula Rothlisberger* ${ }^{\dagger}$ \\ ${ }^{\dagger}$ Laboratory of Computational Chemistry and Biochemistry LCBC, ISIC, FSB BSP, Ecole Polytechnique Fédérale de Lausanne \\ (EPFL), CH-1015 Lausanne, Switzerland \\ ${ }^{\ddagger}$ Department of Fundamental Chemistry, Federal University of Pernambuco, Recife 50740-560, Brazil
}

Supporting Information

\begin{abstract}
Compounds bearing tetrazole rings are valuable facets in numerous branches of chemistry including metabolic imaging and the production of drugs and highenergy materials. Synthesis of tetrazoles with the help of organocatalysts has intensively been explored, while enzyme-directed click chemistry has attracted less attention and was only used in inhibitor design so far. Herein, we have investigated the possibility of a biomimetic catalyst based on a Lewis acid approach by exploring the anionic cycloaddition of azide and acetonitrile catalyzed by $\mathrm{ZnBr}_{2}$ in comparison with different biomimetic $\mathrm{Zn}$ (II) models. Density functional based calculations in the gas phase and with implicit solvation indicate that a variety of bioinspired zinc complexes should be able to catalyze tetrazole formation with catalytic enhancements comparable to zinc bromide salts. Such bioinspired routes could provide new possibilities for the stereo- and regioselectively controlled synthesis of tetrazoles.
\end{abstract}

\section{INTRODUCTION}

Many types of heterocyclic compounds play an important role in biology, organic and coordination chemistry, pharmacology, and materials science. ${ }^{1}$ Among them, compounds rich in nitrogen, in particular, tetrazole derivatives, are essential building blocks for asymmetric reactions, ${ }^{2}$ for the synthesis of energetic salts, ${ }^{3,4}$ and blue light-emitting devices. ${ }^{5}$ Furthermore, they play important roles in bioisosterism ${ }^{6}$ and inhibitor design. As a result, in recent years the interest to form such heterocycles via efficient routes has raised remarkably (see Scheme 1). ${ }^{8}$ The most popular method to synthesize tetrazoles is currently the reaction of azides with nitrile moieties. $^{9-14}$ Though this strategy can be applied in several ways, two elegant routes are the use of 1) Lewis acids ${ }^{15}$ and 2) in situ click chemistry.

The first one of these routes was reported by Sharpless and co-workers in $2001 .^{16}$ In this study, a variety of nitriles were transformed into their corresponding $1 \mathrm{H}$-tetrazoles by using zinc salts as catalysts in water. Later, the reaction mechanism underlying the transformation of azides and nitriles via the addition of Lewis acids such as $\mathrm{ZnBr}_{2}$ and $\mathrm{AlCl}_{3}$ was investigated theoretically with density functional theory. ${ }^{17}$ Three possible scenarios for the generation of $1 \mathrm{H}$-tetrazoles were proposed in which the zinc ion is coordinated by either the nitrile moiety, the azide moiety, or both. It was hypothesized that coordination of $\mathrm{Zn}^{2+}$ ion via the nitrile group increases the rate of reaction in contrast to coordination via the azide group.

On the other hand, in situ click chemistry appears as a viable environmentally friendly and potentially regio- and stereoselective alternative to produce tetrazole derivatives by exploiting the power of biocatalysis. In 2002, it was
Scheme 1. Selected Examples of $(3+2)$ Cycloaddition Reactions of Sodium Azide and Alkynes with Different Approaches: a) the High-Temperature Microreactor Method, ${ }^{18}$ b) Trimethylsilylazide/Trimethylaluminum, ${ }^{19}$ c) $\mathrm{ZnBr}_{2}{ }^{9}$ and d) Iodine Catalysis ${ }^{20 a}$

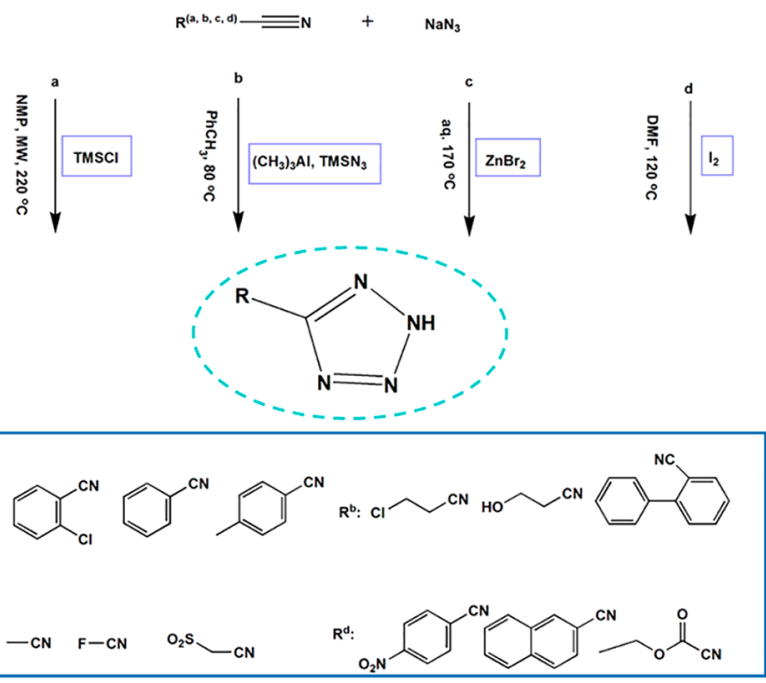

${ }^{a}$ Three representative alkyne substrates are shown for each method.

demonstrated for the first time that acetylcholinesterase can promote this type of cyclization reactions by producing a mixture of syn and anti triazoles. ${ }^{21}$ In another study, the

Received: July 31, 2017

Published: October 26, 2017 

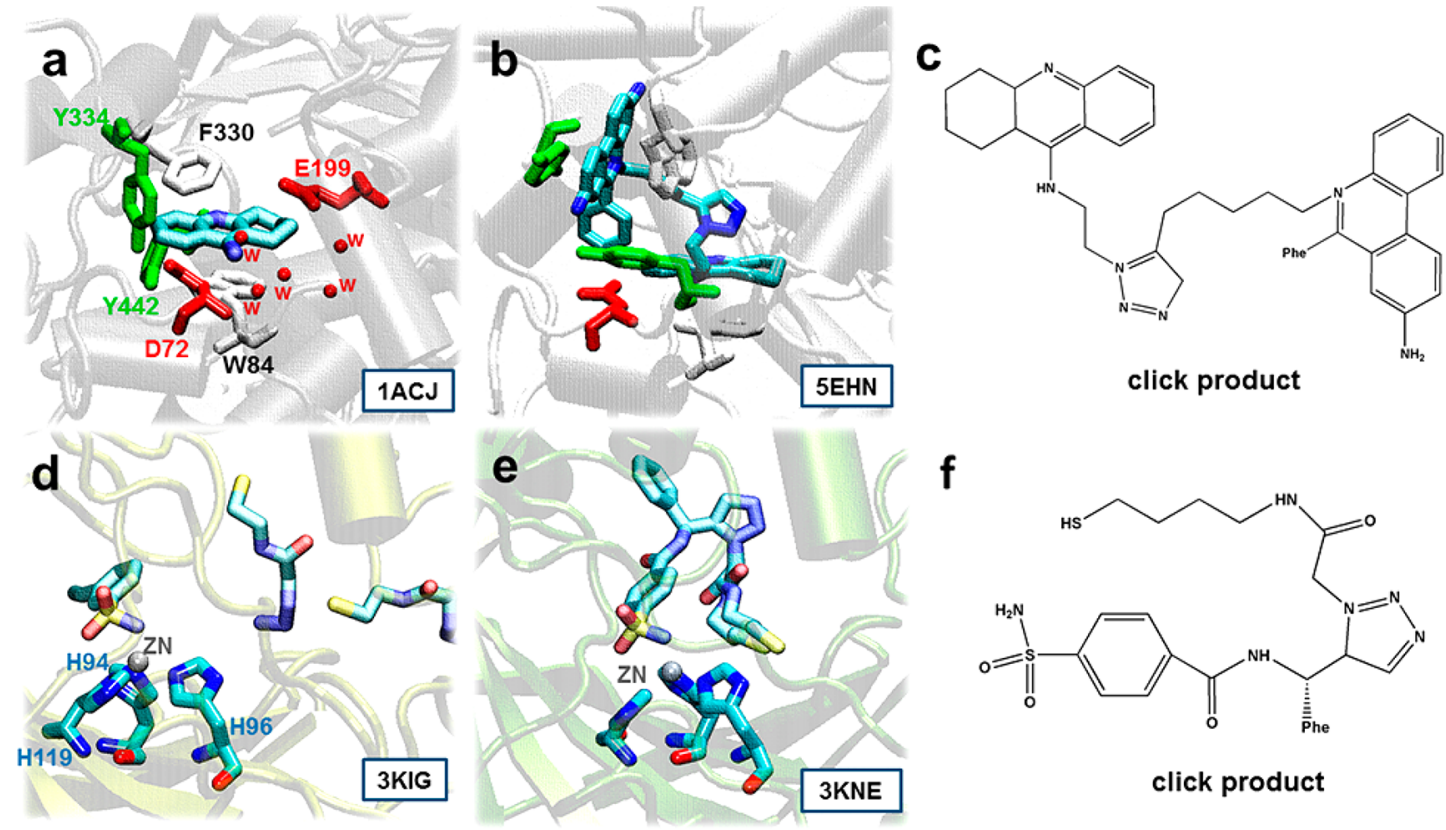

Figure 1. Active site X-ray crystal structures of acetylcholine esterase a) with quaternary ligand, ${ }^{25}$ b) with triazole inhibitor, ${ }^{26}$ c) the resulting inhibitor contains the tacrine motif, an acetylcholine esterase inhibitor and carbonic anhydrase II mutant d) with an alkyne and a covalently attached azide, ${ }^{23}$ e) with formed triazole, ${ }^{23}$ f) structure of the product. Corresponding PDB codes are listed in the figure.

Sharpless group used cowpea mosaic virus (CPMV) as a biological scaffold to perform $\mathrm{Cu}(\mathrm{I})$ catalyzed alkyne-azide cycloaddition via ligation. ${ }^{22}$ In addition, bovine carbonic anhydrase II (bHCA II) and engineered human carbonic anhydrase II (HCA II) were both reported as suitable reaction vessels for the 1,3-dipolar cycloaddition reaction ${ }^{23}$ shown in Figure 1, and very recently cyclooxygenase- 2 isozyme was successfully used for kinetic target-guided synthesis ${ }^{24}$ i.e. in situ click chemistry. However, in all cases, the formed cycloadducts act as selective inhibitors of the corresponding enzymes rendering these routes unattractive for the purpose of chemical synthesis. Besides, in some cases, the substrates need to be modified chemically. For example, in the case of carbonic anhydrase II, the azide component has to be attached covalently to the protein through a propylene disulfide linker. Moreover, the alkyne moiety should possess a sulfonamide group in order to coordinate the $\mathrm{Zn}^{2+}$ ion. Besides that, the restriction to the conversion of activated alkyne and azide groups is another shortcoming.

Here, we perform a systematic computational study on a series of bioinspired zinc complexes as Lewis acid catalysts to (i) understand and analyze the factors that are responsible for the catalytic enhancement for cycloaddition reactions and (ii) identify new mild and general routes for the biomimetic production of tetrazoles especially for the case of inactivated nitriles and azides, ${ }^{27}$ where the use of high pressure and temperatures, long reaction times, and low yields still constitute major bottlenecks. ${ }^{15,28}$

We started our investigation by examining the uncatalyzed reactions, followed by $\mathrm{ZnBr}_{2}$ promoted route to unravel the detailed mechanism and the essential factors influencing catalysis. The gained knowledge was taken as a base for the subsequent investigation of a series of potential biomimetic zinc catalysts for tetrazole formation. As a result of these computational investigations, we propose a bioinspired complex with a mononuclear zinc binding site which contains an unnatural 4-(di)fluoro-DL-glutamic acid ligand as a promising catalyst for tetrazole formation via $(3+2)$ cycloaddition.

\section{COMPUTATIONAL DETAILS}

Gaussian $09^{29}$ was used to perform all DFT calculations. For the uncatalyzed reactions, the geometries of reactants, transition states, and products were optimized at the following levels: 1) B3LYP/6-311G**, 2) B3LYP/6-31+G*, 3) M06-2X/ 6-311G**, 4) CBS-QB3, ${ }^{30}$ and 5) mPW1PW91/6-311G** in the gas phase as well as 6) $\mathrm{SMD}_{\left(\mathrm{H}_{2} \mathrm{O}\right)} / \mathrm{B} 3 \mathrm{LYP} / 6-311 \mathrm{G}^{* *}$ and 7) $\mathrm{SMD}_{\mathrm{DMF}} / \mathrm{B} 3 \mathrm{LYP} / 6-311 \mathrm{G}^{* *}$ in implicit solvent with UFF radii. ${ }^{31}$ For the $\mathrm{Zn}^{2+}$ catalyzed reactions, geometry optimizations were conducted in the gas phase using different methods: 1) $\left.\mathrm{B} 3 \mathrm{LYP} / 6-311 \mathrm{G}^{* *}, 2\right)$ the B3LYP functional with the “double- $\xi$ " quality LANL2DZ basis set and LANL2DZ pseudopotential, and 3) the B3LYP functional with the SDD basis set and SDD pseudopotential for the metal atom and a 6$311 \mathrm{G}^{* *}$ basis set for all other atoms. The success of the B3LYP functional to accurately treat zinc complexes has been previously demonstrated. ${ }^{32-35}$ It has also been extensively employed to investigate the catalytic mechanism of zinc containing enzymes. ${ }^{38-39}$ Transition states were characterized by a single imaginary frequency. Intrinsic reaction coordinate (IRC) scans were performed when necessary to ensure that the TSs led to the correct minima. Thermodynamic corrections were computed at standard temperature and pressure. For zinc mediated reactions, the solvent effects were included by single point calculations (B3LYP/6-311+G**) on the gas-phase stationary points (B3LYP/LANL2DZ-6-311G**) with a SMD continuum solvation model. ${ }^{40,41}$ All zinc containing structures discussed in the text were optimized by B3LYP/ LANL2DZ-6-311G** level of theory. We calculated the overall activation energy barriers based on zinc bound azide complex and acetonitrile molecule, since they are the most stable species in solution. The same approach was followed for the Lewis acid promoted azide-nitrile cycloaddition reactions through DFT 

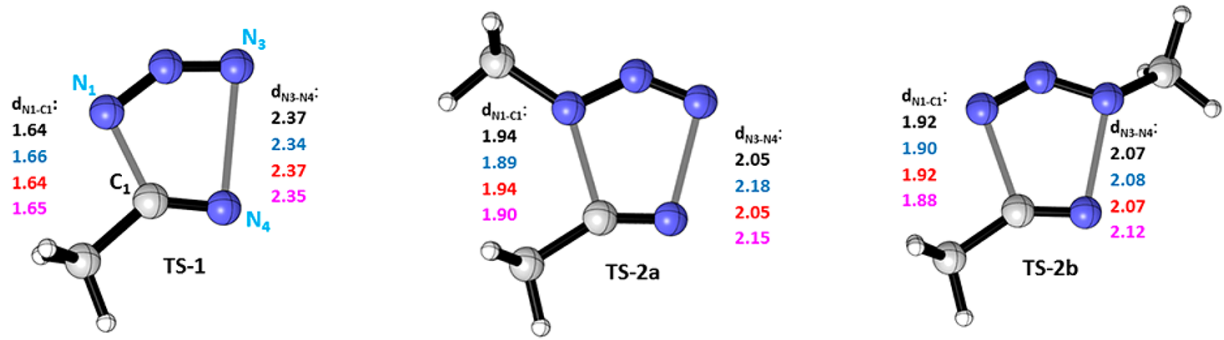

\begin{tabular}{|c|c|c|c|c|c|c|c|c|c|c|c|}
\hline$\Delta \mathbf{G}^{\ddagger}$ & $\Delta \mathrm{H}^{\ddagger}$ & $\Delta G_{\mathrm{rnn}}$ & $\Delta \mathrm{H}_{\mathrm{r} \times \mathrm{n}}$ & $\Delta \mathbf{G}^{\ddagger}$ & $\Delta \mathbf{H}^{ \pm}$ & $\Delta G_{\mathrm{r} \times \mathrm{n}}$ & $\Delta \mathrm{H}_{\mathrm{rxn}}$ & $\Delta \mathbf{G}^{ \pm}$ & $\Delta \mathbf{H}^{\ddagger}$ & $\Delta \mathrm{G}_{\mathrm{rxn}}$ & $\Delta H_{r \times n}$ \\
\hline 28.1 & 17.8 & -14.3 & -25.0 & 39.3 & 28.3 & -5.0 & -18.0 & 44.3 & 32.6 & -9.3 & -21.9 \\
\hline 40.4 & 29.6 & -10.0 & -21.4 & 40.9 & 28.7 & -12.3 & -27.1 & 48.1 & 35.9 & -12.5 & -25.9 \\
\hline 27.0 & 16.8 & -20.2 & -30.9 & 36.2 & 25.2 & -13.6 & -26.6 & 39.3 & 27.5 & -17.5 & -30.0 \\
\hline 38.6 & 28.2 & -5.7 & -16.5 & 40.0 & 28.7 & -7.4 & -22.0 & 47.3 & 35.3 & -8.0 & -21.2 \\
\hline
\end{tabular}

Figure 2. Located transition state geometries for the intermolecular $(3+2)$ cycloaddition of a prototypical (in)organic azide and nitrile with different methods and basis sets. The corresponding activation $\left(\left(\Delta G^{\ddagger}\right)\right.$ and $\left(\left(\Delta H^{\ddagger}\right)\right)$ and reaction (free) energies $\left(\left(\Delta G_{\mathrm{rxn}}\right)\right.$ and $\left.\left(\Delta H_{\mathrm{rxn}}\right)\right)$ are given in $\mathrm{kcal} / \mathrm{mol}$.
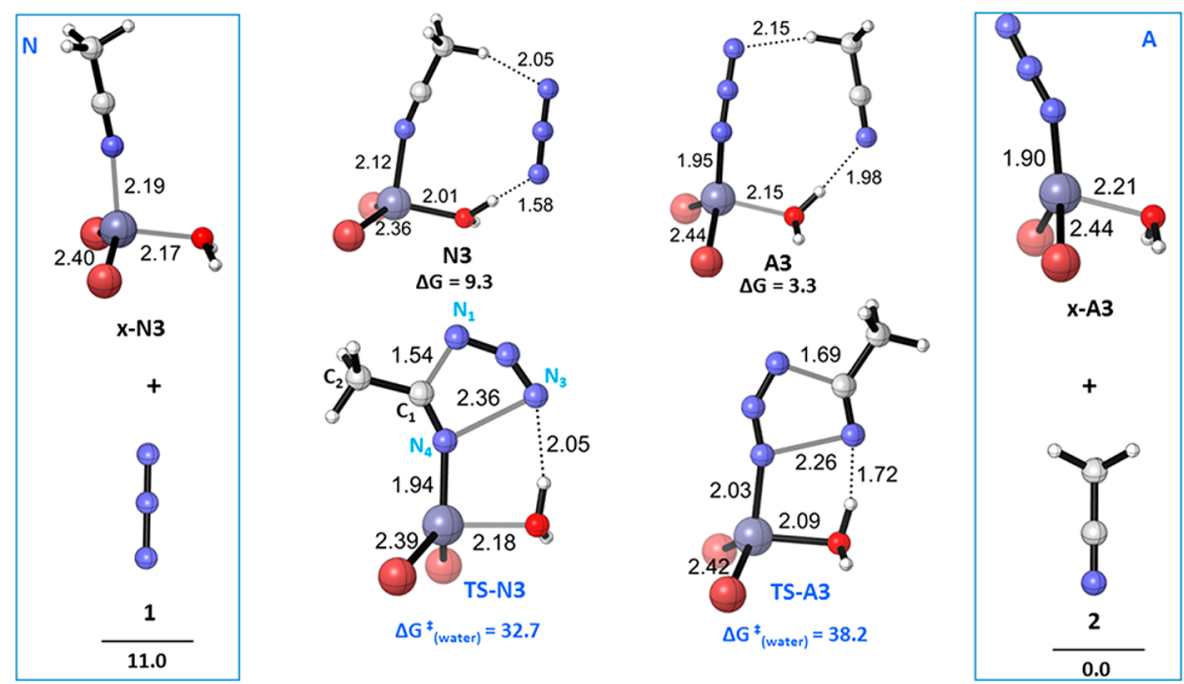

Figure 3. Located reactants, intermediates, and transition state structures for the intermolecular $(3+2)$ cycloaddition of anionic azide and nitrile catalyzed by zinc(II) salt. Numbers refer to relative free energies by single point solvent calculations with respect to the system $\mathbf{x}$-A3 $+\mathbf{2}$.

calculations before. ${ }^{44}$ The energies of cycloadducts were also investigated and listed in the Supporting Information. The CYLVIEW software ${ }^{42}$ was used to represent the optimized structures. X-ray structures were rendered by using VMD. ${ }^{43}$ All calculated reaction barriers given in the figures and tables are in $\mathrm{kcal} / \mathrm{mol}$. All characteristic distances are given in Angstroms.

\section{RESULTS AND DISCUSSION}

3.1. Uncatalyzed Reactions. First, we performed calculations for the (uncatalyzed) reactions between an (in)organic azide and a nitrile group (Figure 2). Our results are in agreement with previous computational findings $9,17,44,45$ showing that addition of azide anion and organic azide to a nitrile moiety proceeds via a concerted mechanism. Synchronous transition states were located in the cycloaddition reaction between neutral azide and a nitrile group, whereas the transition states determined for the reaction involving the anionic azide were asynchronous.

Overall all tested methods are in fairly close agreement, predicting activation free energies of the order of $25-30 \mathrm{kcal} /$ mol for the uncatalyzed gas-phase reaction (results for all tested methods are given in the Supporting Information). In case of the reaction with inorganic azide anion, B3LYP with a diffuse basis set gives slightly larger activation barriers (see the Supporting Information). The CBS-QB3 approach predicts activation and reaction barriers similar to the DFT based methods, whereas the lowest activation energies were calculated at the mPW1PW91 level (see the SI). We also examined the effect of solvent, and as can be expected, it is pronounced for this anionic cycloaddition reaction. Typically, the activation free energy barriers are roughly $9-10 \mathrm{kcal} / \mathrm{mol}$ higher than the gasphase values.

For the reactions with neutral azide, formation of two isomers is possible yielding 1,5- (TS-2a) and 2,5-disubstituted (TS-2b) tetrazoles. TS-2a is more favorable, which is consistent with previous experimental and computational data. ${ }^{9}$ The difference ranges from 4.3 to $7.4 \mathrm{kcal} / \mathrm{mol}$ in the activation energy barrier depending on the methodology used (Figure 2). In the gas phase, the tetrazole product resulting from $\mathbf{T S}-\mathbf{2} \mathbf{b}$ is more stable than the one formed via TS-2a. The stability 


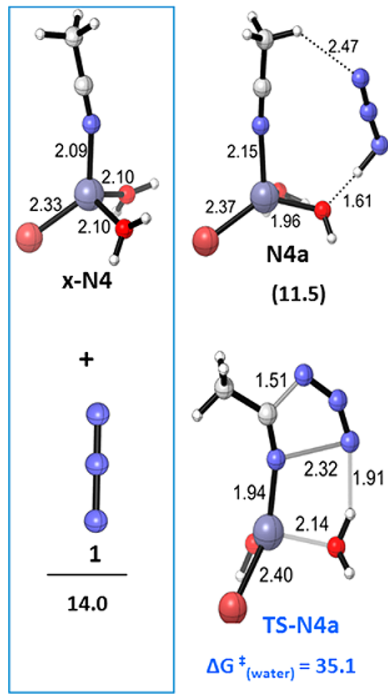

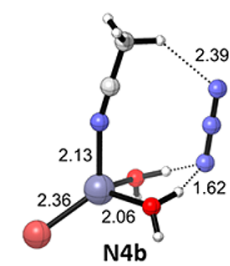

(4.5)

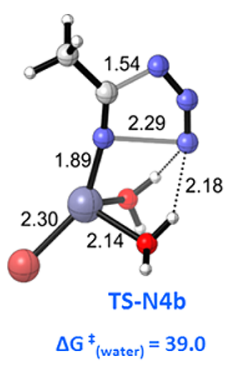

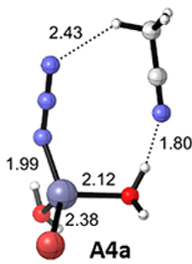

(1.2)

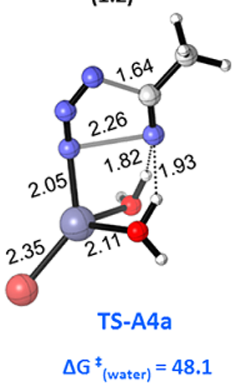

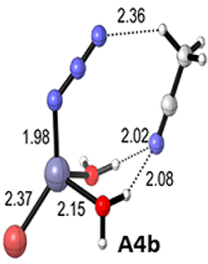

$(0.0)$

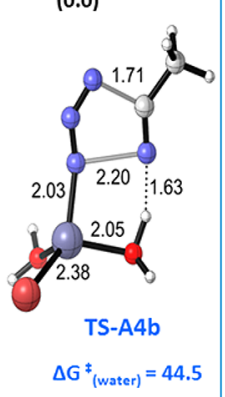

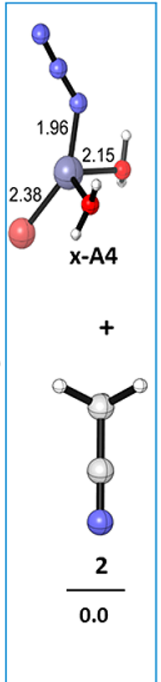

Figure 4. Zinc-catalyzed intermolecular $(3+2)$ cycloaddition of inorganic azide and nitrile. Two water molecules and one bromide ion are included in the coordination shell. The relative free energies of intermediates by single point solvent calculations are given in parentheses.

difference is reduced when solvent effects are included and seems to be a delicate balance between entropic contributions and enthalpic effects, e.g. for the experimentally used solvent DMF $(\varepsilon=37.2)$, the product of transition state TS-2a is enthalpically slightly favored (by $\Delta \Delta H_{\mathrm{rxn}}=-0.8 \mathrm{kcal} / \mathrm{mol}$, similar to the reaction enthalpy difference reported in ref 9 obtained via single point calculations with the COSMO model).

3.2. Catalyzed Reactions. 3.2.1. Zinc Bromide: An Old Story Retold. Next, we performed DFT calculations for the binding of inorganic azide and nitrile to $\mathrm{ZnBr}_{2}$ to understand the origins of the catalytic rate enhancement observed via Lewis acid catalysis.

The $(3+2)$ cycloaddition transition state structures located with several DFT methods are similar to those reported by Himo et al. ${ }^{17}$ However, we find two new intermediates which are pseudocyclic and comprise hydrogen bonding interactions. In 2012, Kappe et al. have discussed the reaction intermediates for $\mathrm{ZnBr}_{2}$ and $\mathrm{AlCl}_{3}$ promoted 1,3-dipolar cycloadditions of benzonitrile with azide. ${ }^{44}$ Formation of intermediates and weak complexes for different cycloaddition reactions has been reported before. ${ }^{70,71}$

The optimized geometries are given in Figures 3 and 4; associated energies and dipole moments obtained with different methods in the gas phase are summarized in Tables 1 and 2, respectively.

To have a common energy origin, we have defined the total (free) energy of the system $\mathbf{x}-\mathbf{A} \mathbf{3}+\mathbf{2}$ at the $\operatorname{SMD}$ (water)/ B3LYP/6-311+G**//B3LYP/LANL2DZ-6-311G** level as zero. With respect to this, the nitrile complex $\mathrm{x}-\mathrm{N} 3$ plus a free azide A3 lies $11 \mathrm{kcal} / \mathrm{mol}$ higher in energy.

The formation of intermediate $\mathbf{N} 3$ from $\mathbf{x}-\mathbf{N} 3$ is slightly exothermic with a $\Delta G$ of $-1.7 \mathrm{kcal} / \mathrm{mol}$, whereas it is slightly endothermic for azide coordination $(3.3 \mathrm{kcal} / \mathrm{mol}$ ) (from $\mathbf{A} 3$ to $\mathbf{x}-\mathbf{A 3}$ ). All calculations predict similar structures for nitrile and azide binding geometries; in both cases a hydrogen bonding interaction with a water molecule is present for the energetically most stable conformers that is also maintained in the transition states. However, the $\mathbf{N}_{1}-\mathbf{C}_{1}$ distance is shorter and the $\mathbf{N}_{3}-\mathbf{N}_{4}$ bond distance (Figure 3) is longer in TS-N3 compared to TS-A3 indicating an early transition state and suggesting a lower energy barrier. We have also found that the dipole moments of the azide binding transition states are higher than in the case of nitrile coordination. This higher dipole moment of the azide coordination is likely another reason for its destabilization in the gas phase (Table 2).

Next we investigated the same reaction with a bromo-diaqua zinc complex as catalyst. In both cases, nitrile binding transition states (TS-N3 and TS-N4) are lower than the azide binding ones. Again, the complex and transition state structures are characterized by intramolecular hydrogen bonds between the aqua ligands and the azide, respectively, in the nitrile unit. In some cases, these hydrogen bonds are exceptionally strong leading to spontaneous proton transfer. Among those, complex N4a in which the azide group abstracts a proton was found be higher in energy with respect to A4a, thereby lowering the energy barrier (TS-N4a is $3 \mathrm{kcal} / \mathrm{mol}$ lower in energy than the transition state structure TS-A4a resulting from complex A4a). The same relation is observed between the relative energies of the adduct complexes N4a $>\mathbf{N} 4 \mathbf{b}$ and the corresponding barriers TS-N4a $<$ TS-N4b.

The higher stability of the adduct complex N4b can be attributed not only to additional hydrogen bonding interaction but also to the more ionic character of the $\mathrm{Zn}-\mathrm{N}_{4}$ bond. An $\mathrm{NBO}$ analysis at the (B3LYP/LANL2DZ-6-311G**) level indicates that natural atomic charges on the $\mathrm{Zn}$ and the $\mathrm{N}_{4}$ atoms of $\mathrm{N4a}$ are $1.18 \mathrm{e}$ and $-0.47 \mathrm{e}$, respectively, whereas the charges on the corresponding atoms of $\mathrm{N} 4 \mathrm{~b}$ are $1.23 \mathrm{e}$ and $-0.49 \mathrm{e}$. The zinc-azide bond is also more ionic in intermediate structure A4b (charges of $1.20 \mathrm{e}$ and $-0.72 \mathrm{e}$ ) than in $\mathbf{A 4 a}$ (1.21e and $-0.66 \mathrm{e})$. H-bonding is shown to be especially significant in N3 and A4a with the H-bond length decreasing from 2.05 to $1.58 \AA$ and 1.91 to $1.61 \AA$, respectively, when going from the transition states to the intermediate states.

3.2.2. Are Biomimetic Zinc Complexes Able To Catalyze Tetrazole Formation? The zinc salt based Lewis acid catalysis introduced by Sharpless has found widespread use in organic chemistry for the formation of tetrazoles. Though encouraging results have been reported, most of the synthetic protocols need relatively long reaction times, elevated temperatures, and the use of toxic solvents and result in low yields and isomeric mixtures. ${ }^{46}$ Biocatalysis which has gained importance in organic 
Table 1. Calculated Free Energies and Enthalpies for the Intermediates, the Lowest Transition States and Cycloadducts for the Cycloaddition of Azide Anion with Acetonitrile Catalyzed by Zinc(II) Salt in the Gas Phase

\begin{tabular}{|c|c|c|c|c|}
\hline \multirow[b]{2}{*}{ method } & \multicolumn{2}{|c|}{ nitrile coordination } & \multicolumn{2}{|c|}{ azide coordination } \\
\hline & $\Delta G_{(298 \mathrm{~K})}$ & $\Delta H_{(298 \mathrm{~K})}$ & $\Delta G_{(298 \mathrm{~K})}$ & $\Delta H_{(298 \mathrm{~K})}$ \\
\hline \multicolumn{5}{|c|}{$2 \mathrm{Br}^{-}+1$ Water } \\
\hline \multicolumn{5}{|c|}{ X-N3 or X-A3 + Azide or Nitrile $\rightarrow$ N3 or A4 } \\
\hline B3LYP/6-311G** & -37.4 & -48.9 & 1.2 & -7.8 \\
\hline B3LYP/LANL2DZ-6-311G** & -37.9 & -49.4 & -0.1 & -6.8 \\
\hline B3LYP/SDD-6-311G** & -35.6 & -47.1 & 3.3 & -6.0 \\
\hline $\begin{array}{l}\text { M062X/LANL2DZ-6- } \\
\text { 311G** }\end{array}$ & -39.9 & -51.8 & -2.3 & -13.2 \\
\hline CBS-Q3 & -30.8 & -41.9 & 2.1 & -6.4 \\
\hline \multicolumn{5}{|c|}{$\mathrm{N} 3$ or $\mathrm{A} 4 \rightarrow \mathrm{TS}-\mathrm{N} 3$ or TS-A3 } \\
\hline B3LYP/6-311G** & 18.9 & 16.5 & 33.7 & 29.4 \\
\hline B3LYP/LANL2DZ-6-311G** & 19.5 & 17.2 & 32.7 & 29.0 \\
\hline B3LYP/SDD-6-311G** & 18.0 & 15.7 & 33.4 & 29.8 \\
\hline $\begin{array}{l}\text { M062X/LANL2DZ-6- } \\
\text { 311G** }\end{array}$ & 17.8 & 15.8 & 32.0 & 29.5 \\
\hline CBS-Q3 & 14.1 & 11.6 & 29.5 & 25.1 \\
\hline \multicolumn{5}{|c|}{ X-N3 or X-A3 + Azide or Nitrile $\rightarrow$ Cycloadduct } \\
\hline B3LYP/6-311G** & -56.7 & -72.3 & -10.2 & -24.6 \\
\hline B3LYP/LANL2DZ-6-311G** & -56.2 & -72.0 & -11.4 & -23.4 \\
\hline B3LYP/SDD-6-311G** & -55.1 & -70.9 & -9.0 & -22.8 \\
\hline $\begin{array}{l}\text { M062X/LANL2DZ-6- } \\
\text { 311G** }\end{array}$ & -67.9 & -83.7 & -19.4 & -34.2 \\
\hline CBS-Q3 & -59.6 & -74.9 & -17.5 & -31.7 \\
\hline \multicolumn{5}{|c|}{$1 \mathrm{Br}^{-}+2$ Water } \\
\hline \multicolumn{5}{|c|}{ X-N4a or X-A4a + Azide or Nitrile $\rightarrow$ N4a or A4a } \\
\hline B3LYP/6-311G** & & & -3.3 & -13.2 \\
\hline B3LYP/LANL2DZ-6-311G*** & -113.0 & -126.4 & -3.2 & -14.3 \\
\hline B3LYP/SDD-6-311G** & -116.3 & -128.2 & -2.0 & -12.0 \\
\hline $\begin{array}{l}\text { M062X/LANL2DZ-6- } \\
\text { 311G** }\end{array}$ & & & -6.0 & -16.3 \\
\hline CBS-Q3 & -109.1 & -121.4 & -1.2 & -11.7 \\
\hline \multicolumn{5}{|c|}{$\mathrm{N} 4 \mathrm{a}$ or $\mathrm{A} 4 \mathrm{a} \rightarrow \mathrm{TS}-\mathrm{N} 4 \mathrm{a}$ or TS-A4a } \\
\hline $\mathrm{B} 3 \mathrm{LYP} / 6-311 \mathrm{G}^{* *}$ & & - & 37.2 & 32.6 \\
\hline B3LYP/LANL2DZ-6-311G** & 20.8 & 18.9 & 36.9 & 31.9 \\
\hline B3LYP/SDD-6-311G** & 20.7 & 18.1 & 38.1 & 33.4 \\
\hline $\begin{array}{l}\text { M062X/LANL2DZ-6- } \\
\text { 311G** }\end{array}$ & & & 36.5 & 33.3 \\
\hline CBS-Q3 & 17.8 & 15.4 & 33.4 & 29.0 \\
\hline \multicolumn{5}{|c|}{ X-N4a or X-A4a + Azide or Nitrile $\rightarrow$ Cycloadduct } \\
\hline B3LYP/6-311G** & & & -8.4 & -22.9 \\
\hline B3LYP/LANL2DZ-6-311G** & -125.4 & -142.1 & -10.1 & -25.1 \\
\hline B3LYP/SDD-6-311G** & -128.1 & -144.3 & -7.8 & -21.6 \\
\hline $\begin{array}{l}\text { M062X/LANL2DZ-6- } \\
\text { 311G** }\end{array}$ & & & -18.9 & -36.7 \\
\hline CBS-Q3 & -128.9 & -144.9 & -14.7 & -29.5 \\
\hline
\end{tabular}

chemistry for green and selective synthesis ${ }^{47}$ might constitute an interesting alternative to circumvent some of these problems. Intriguingly, there are several natural ${ }^{48-54}$ and de novo designed enzymes ${ }^{55-58}$ that perform cycloaddition reactions. It is worth underlining that carbonic anhydrase can serve as a multipurpose catalyst, and it has been modified to perform different reactions, ${ }^{59-64}$ either by amino acid mutation or metal substitution. Besides, there are many notable examples for different proteins ${ }^{65-69}$ that show a change in catalytic activity by altering single residue.

To explore possible bioinspired routes to tetrazole formation, we have investigated ten different zinc complexes as possible catalysts, (i) $\mathrm{Zn}-\mathrm{His}_{2} \mathrm{Wat}$, (ii) $\mathrm{Zn}-\mathrm{His}_{2} \mathrm{Wat}_{2}$, (iii) $\mathrm{Zn}-\mathrm{HisCy}$ -
Table 2. Calculated Dipole Moments (debye) for the Azide and Nitrile Binding Transition State Structures

\begin{tabular}{lcc}
\multicolumn{1}{c}{ method } & TS-N3 & TS-A3 \\
\hline B3LYP/6-311G** & 1.9 & 4.4 \\
B3LYP/LANL2DZ-6-311G** & 1.8 & 4.5 \\
B3LYP/SDD-6-311G** & 1.3 & 4.3 \\
M062X/LANL2DZ-6-311G** & 3.0 & 4.6 \\
CBS-Q3 & 1.6 & 3.4 \\
method & TS-N4a & TS-A4a \\
B3LYP/6-311G** & & 6.4 \\
B3LYP/LANL2DZ-6-311G** & 4.2 & 5.9 \\
B3LYP/SDD-6-311G** & 4.1 & 5.6 \\
M062X/LANL2DZ-6-311G** & 4.7 & 5.9 \\
CBS-Q3 & 4.0 & 5.5 \\
\hline
\end{tabular}

sWat, (iv) Zn-His ${ }_{2}$ Cys, (v) Zn-CysWat 2 , vi) Zn-His 2 Glu, vii) $\mathrm{Zn}-\mathrm{His}_{3}$, and three complexes containing unnatural modified amino acids, 2,2'-bipyridin-5yl)alanine (BpyAla), 4-fluoro-DLglutamate, and 4,4-difluoro-DL-glutamate.

Figures 5 and 6 show the determined transition states and intermediate structures for nitrile and azide coordination. All transition states are concerted. The dissymmetry of the two bonds formed in the TSs increases in the case of nitrile coordination. Nitrile coordination is strongly preferred over azide coordination in all cases, and activation energy barriers in Figure 5 are comparable to the $\mathrm{ZnBr}_{2}$ catalyst with overall Gibbs free energy barriers for the $(3+2)$ cycloaddition that range from 38.2 to $34.3 \mathrm{kcal} / \mathrm{mol}$ and from 38.3 to $47.9 \mathrm{kcal} /$ mol for the nitrile and azide binding routes, respectively.

Nitrile coordination is favored by 9.1 and $7.7 \mathrm{kcal} / \mathrm{mol}$ in $\mathrm{Zn}$ $\mathrm{His}_{2} \mathrm{Cys}$ and $\mathrm{Zn}-\mathrm{His}_{2} \mathrm{Glu}$. Additionally, we examined the effect of unnatural glutamic acid derivatives. In view of the strong electronegativity of the fluorine atom, 4-fluoro-DL-glutamic acid was investigated. It turns out that the overall energy barriers (with respect to $\mathrm{x}-\mathrm{A} 3+$ nitrile reference) are not significantly affected by fluorine atom substitution; however, the barrier of the rate-determining step (from the adduct complex to the transition state) can vary substantially. The lowest activation energy with an overall barrier of $34.3 \mathrm{kcal} / \mathrm{mol}$ and a barrier for the rate-determining step of only $13.6 \mathrm{kcal} / \mathrm{mol}$ was achieved by including 4-(di)fluoro-DL-glutamic acid substitution to the zinc coordination sphere, TS-N12. The overall barriers are very similar to the $\mathrm{ZnBr}_{2}$ catalyzed reaction, but the formation of the transition state from the adduct complex is substantially lower with respect to the $\mathrm{ZnBr}_{2}$ case $(21.7 \mathrm{kcal} / \mathrm{mol})$. We analyzed the adduct complex and transition state structures in comparison to $\mathrm{ZnBr}_{2}$. The transition state (TS-N12?) and the one found for $\mathrm{ZnBr}_{2}$ (TS-N3) are very similar in terms of synchronicity. The natural atomic charges of the $\mathrm{N}_{1}$ and $\mathrm{N}_{3}$ atoms of the azide group are also similar: -0.43 and -0.18 and -0.41 and -0.15 , respectively. The $\mathbf{C}_{1}-\mathbf{N}_{1}$ bond is more polar for the transition state with the lowest overall activation barrier, TS-N3. This shows the increased polar character of the reaction which can be associated with the rate acceleration of Lewis acid catalyzed cycloadditions. $^{72}$

Lastly, we have calculated the energetics of the cycloaddition reactions shown in Figure 7, starting with an active site model of alpha class HCA II. Toward this end, we replaced the activated water molecule by the nitrile and azide moiety. The overall activation free energy barriers are very high, in fact in the order of the uncatalyzed reaction. We argue that the failure of HCA II to catalyze the $(3+2)$ cycloaddition reaction is due 


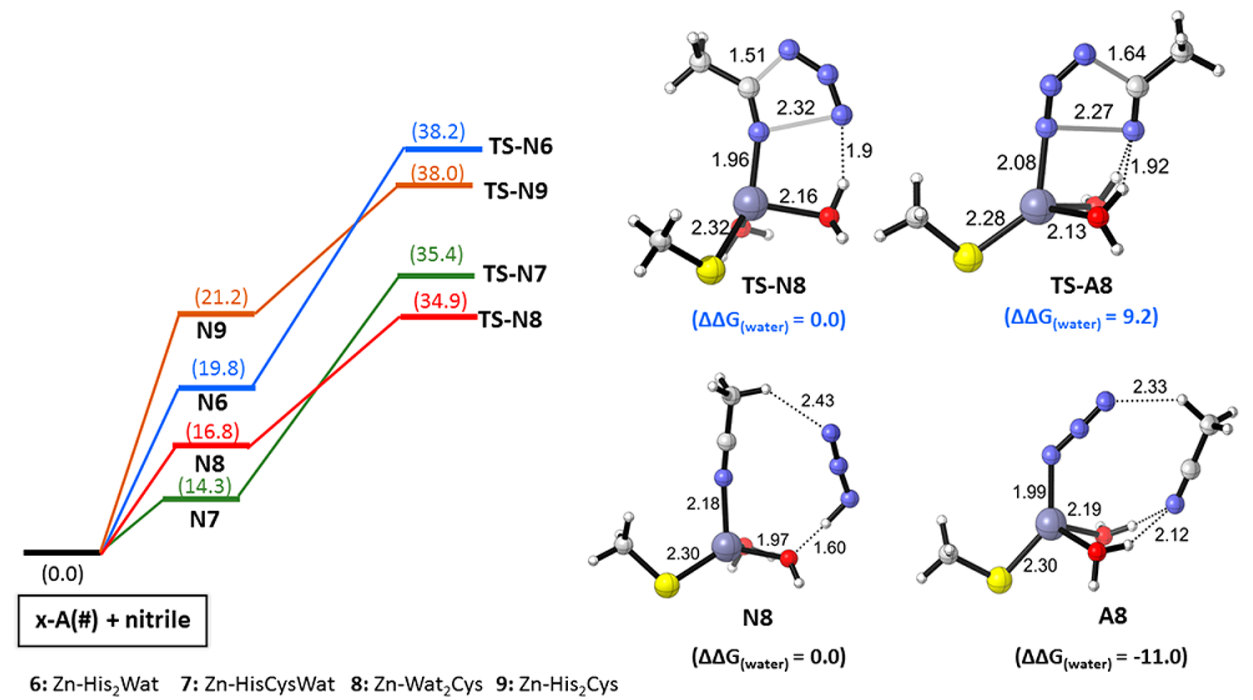

Figure 5. Optimized transition structures and intermediates for the concerted cycloaddition reaction of azide and acetonitrile with CysWat ${ }_{2}$. Free energies (in $\mathrm{kcal} / \mathrm{mol}$ ) for different zinc complexes are computed at the SMD(water)/B3LYP/6-311+G**//B3LYP/LANL2DZ-6-311G** with the corresponding $\mathrm{x}-\mathrm{A} \#+$ nitrile taken as energy origin. Numbers in round brackets are relative energies between corresponding nitrile vs azide complexes.

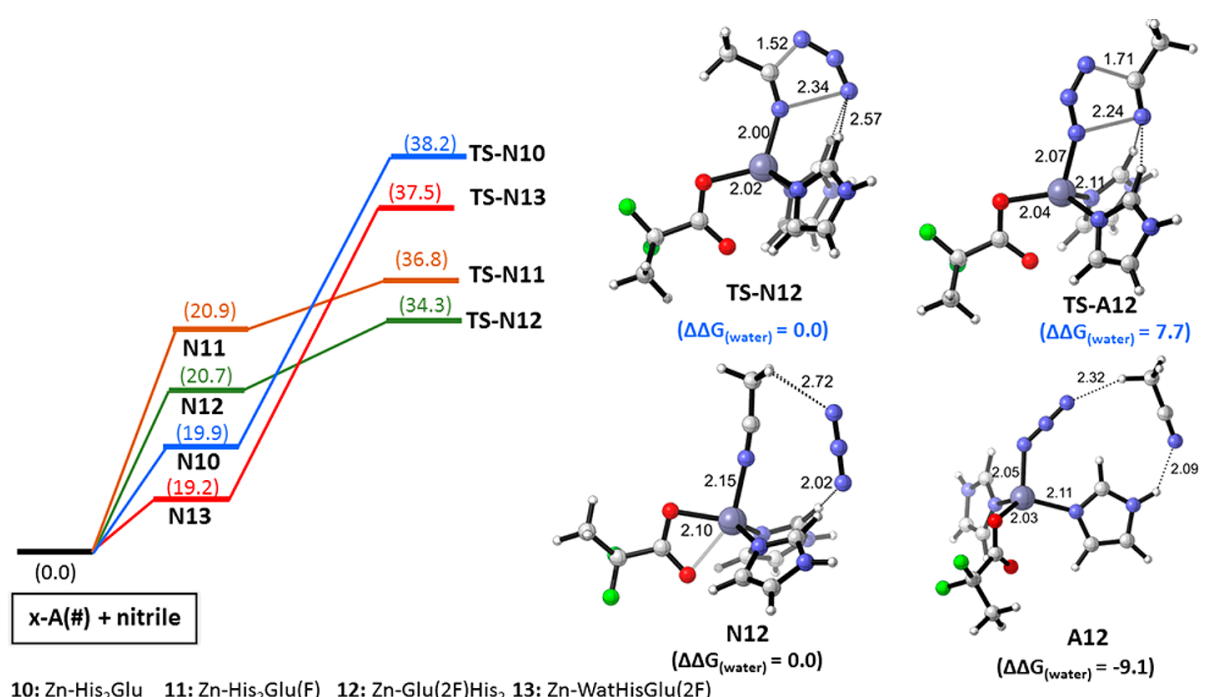

Figure 6. Optimized intermediates and transition structure geometries of (in)organic azide and acetonitrile with $\mathrm{Zn}$ - $\mathrm{His}_{2} \mathrm{Glu}_{\mathrm{u}}$ type zinc complex models. Free energies (in $\mathrm{kcal} / \mathrm{mol}$ ) are computed at the SMD(water)/B3LYP/6-311+G**//B3LYP/LANL2DZ-6-311G** with the corresponding $\mathrm{x}-\mathrm{A} \#+$ nitrile taken as energy origin. Numbers in round brackets are relative energies between corresponding nitrile vs azide complexes.

to the following reason. In this case, it turns out that the nitrile is coordinated to the zinc ion, leading to a pentacoordinated complex in the transition state. In other words, coordination with three histidine residues leads to the case where both reactants are bound to zinc as in NA-14 or NA-15. Therefore, nitrile coordination is hindered which is key to the catalysis. Despite our efforts, it was not possible to locate a nitrile binding adduct complex. To examine the generality of this model, we also investigated the metal binding residue BPyala, which is structurally similar to a histidine residue. As expected, the cycloaddition reaction is computed not to be nitrile selective. Moreover, the Gibbs free energy of activation of the uncatalyzed reaction significantly increases. These results are also in line with the natural atomic charges at the corresponding atoms in the TSs.

First versus second sphere coordination of nitrile appears to be key to catalysis, and the ligands coordinated to the zinc ion can have a significant effect on both coordination preference in the transition state and the corresponding activation barriers. Based on our results, one can speculate that active site of the wild-type HCA II is in fact not ideal to create a favorable nitrile binding concerted transition state. On the other hand, some of the biomimetic zinc complexes, including aspartate/glutamate ligands, have similar catalytic fingerprints as inorganic $\mathrm{ZnBr}_{2}$ salt. Intriguingly, there is a crystal structure (PDB ID: 4YU6, ${ }^{73}$ see Figure $\mathrm{S} 1$ in the SI) available in which a $\mathrm{His}_{2}$ AspWat zinc site is coordinated by an acetonitrile molecule at a distance of 2.1 Å. Besides, a fairly mobile acetonitrile molecule was also located at the zinc active site ( $\left.\mathrm{Zn}-\mathrm{His}_{2} \mathrm{GluWat}\right)$ of thermolysin (PDB ID: $1 \mathrm{FJU}^{74}$ ). Creating an energetically favorable binding cavity also for the azide moiety still remains as an additional challenge. 

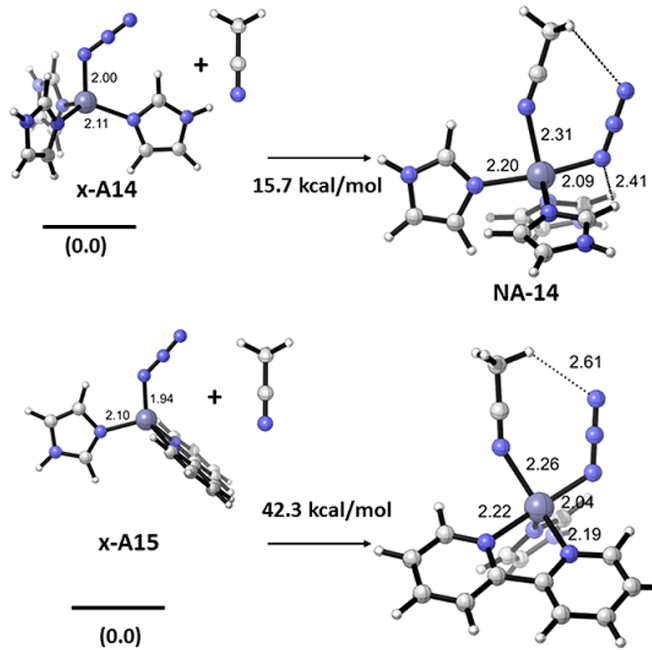

$(0.0)$

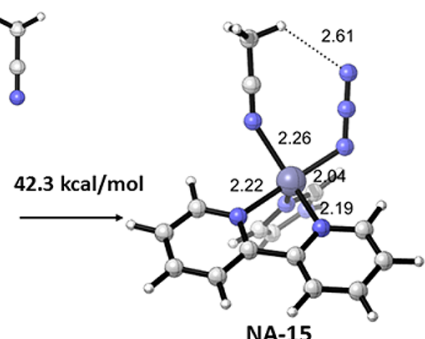

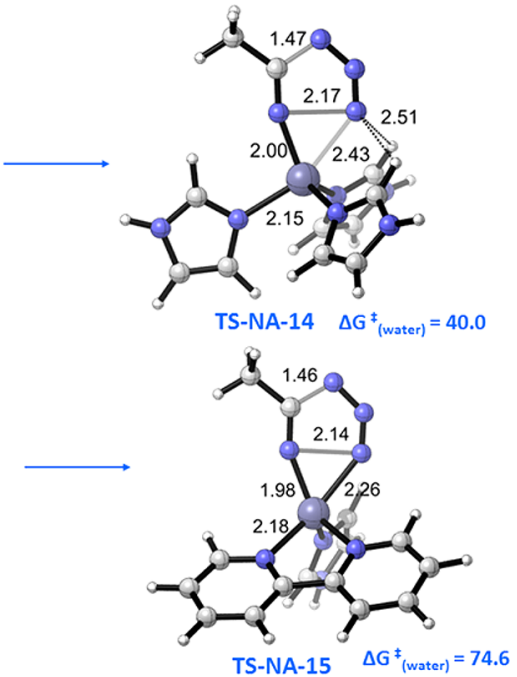

Figure 7. Reactant, intermediate, and transition state structures for an active site model of HCA II and a variant containing the synthetic ligand BPyala. Free energies (in kcal/mol) are computed at the SMD(water)/B3LYP/6-311+G**//B3LYP/LANL2DZ-6-311G** with the corresponding $\mathrm{x}-\mathrm{A \#}+$ nitrile taken as energy origin.

\section{CONCLUSIONS}

The present study is a theoretical comparison of the cycloaddition reaction between azide and nitrile groups by employing $\mathrm{ZnBr}_{2}$ and several biomimetic zinc complexes. Application of biocatalysis in 1,3-dipolar cycloaddition reactions is a relatively new route. The in-depth understanding of the reported reaction mechanisms is important for advancing catalyst engineering. In summary, this work has highlighted that unnatural glutamate derivatives incorporated into the zinc active site might be a good starting point to enable tetrazole formation. A widening of the catalytic repertoire through the introduction of synthetic amino acids appears as a promising route to tailor the properties of proteins. ${ }^{75}$ The efficiency of the proposed systems can be further improved by optimizing the second shell residues in order to favor preferred regioselective intermediates and/or transition state structures and optimally positioned azide binding sites in the protein. This finding may prompt further theoretical and experimental explorations of cycloaddition between simple azides and alkynes that rely on green chemistry.

\section{ASSOCIATED CONTENT}

\section{S Supporting Information}

The Supporting Information is available free of charge on the ACS Publications website at DOI: 10.1021/acs.jctc.7b00819.

Optimized geometries and energies of all computed species (PDF)

\section{AUTHOR INFORMATION}

\section{Corresponding Author}

*E-mail: ursula.roethlisberger@epfl.ch.

\section{ORCID $\odot$}

Esra Bozkurt: 0000-0001-8492-1162

Thereza A. Soares: 0000-0002-5891-6906

\section{Funding}

Financial support from the Swiss National Science Foundation and computational time from the National computing center CSCS are gratefully acknowledged.

\section{Notes}

The authors declare no competing financial interest.

\section{REFERENCES}

(1) Belen'kii, L. I.; Evdokimenkova, Y. B. The Literature of Heterocyclic Chemistry, Part XIII, 2012-2013. Adv. Heterocycl. Chem. 2015, 116, 193-363.

(2) Prieto, A.; Halland, N.; Jørgensen, K. A. Novel ImidazolidineTetrazole Organocatalyst for Asymmetric Conjugate Addition of Nitroalkanes. Org. Lett. 2005, 7 (18), 3897-3900.

(3) Xue, H.; Gao, Y.; Twamley, B.; Shreeve, J. M. New Energetic Salts Based on Nitrogen-Containing Heterocycles. Chem. Mater. 2005, 17 (1), 191-198.

(4) Swain, P. K.; Singh, H.; Tewari, S. P. Energetic Ionic Salts Based on Nitrogen-Rich Heterocycles: A Prospective Study. J. Mol. Liq. 2010, 151, 87-96.

(5) Zink, D. M.; Baumann, T.; Friedrichs, J.; Nieger, M.; Brase, S. Copper(I) Complexes Based on Five-Membered (PN)-N-Boolean AND Heterocycles: Structural Diversity Linked to Exciting Luminescence Properties. Inorg. Chem. 2013, 52 (23), 13509-13520.

(6) Allen, F. H.; Groom, C. R.; Liebeschuetz, J. W.; Bardwell, D. A.; Olsson, T. S. G.; Wood, P. A. The Hydrogen Bond Environments of 1 $\mathrm{H}$-Tetrazole and Tetrazolate Rings: The Structural Basis for Tetrazole-Carboxylic Acid Bioisosterism. J. Chem. Inf. Model. 2012, 52 (3), 857-866

(7) Siles, R.; Kawasaki, Y.; Ross, P.; Freire, E. Synthesis and Biochemical Evaluation of Triazole/tetrazole-Containing Sulfonamides against Thrombin and Related Serine Proteases. Bioorg. Med. Chem. Lett. 2011, 21 (18), 5305-5309.

(8) Candeias, N. R.; Branco, L. C.; Gois, P. M. P.; Afonso, C. A. M.; Trindade, A. F. More Sustainable Approaches for the Synthesis of NBased Heterocycles. Chem. Rev. 2009, 109 (6), 2703-2802.

(9) Himo, F.; Demko, Z. P.; Noodleman, L.; Sharpless, K. B. Mechanisms of Tetrazole Formation by Addition of Azide to Nitriles. J. Am. Chem. Soc. 2002, 124 (41), 12210-12216.

(10) Tron, G. C.; Pirali, T.; Billington, R. A.; Canonico, P. L.; Sorba, G.; Genazzani, A. A. Click Chemistry Reactions in Medicinal Chemistry: Applications of the 1,3-Dipolar Cycloaddition between Azides and Alkynes. Med. Res. Rev. 2008, 28, 278-308.

(11) Kolb, H. C.; Finn, M. G.; Sharpless, K. B. Click Chemistry: Diverse Chemical Function from a Few Good Reactions. Angew. Chem., Int. Ed. 2001, 40, 2004-2021.

(12) Huisgen, R. 1,3???Dipolar Cycloadditions. Past and Future. Angew. Chem., Int. Ed. Engl. 1963, 2 (10), 565-598. 
(13) Wang, Q.; Chittaboina, S.; Barnhill, H. N. Advances in 1,3Dipolar Cycloaddition Reaction of Azides and Alkynes - A Prototype Of "click" chemistry. Lett. Org. Chem. 2005, 2 (4), 293-301.

(14) Aureggi, V.; Sedelmeier, G. 1,3-Dipolar Cycloaddition: Click Chemistry for the Synthesis of 5-Substituted Tetrazoles from Organoaluminum Azides and Nitriles. Angew. Chem., Int. Ed. 2007, 46 (44), 8440-8444.

(15) Roh, J.; Vávrová, K.; Hrabálek, A. Synthesis and Functionalization of 5-Substituted Tetrazoles. Eur. J. Org. Chem. 2012, 2012, 61016118.

(16) Demko, Z. P.; Sharpless, K. B. Preparation of 5-Substituted 1HTetrazoles from Nitriles in Water. J. Org. Chem. 2001, 66 (24), 79457950.

(17) Himo, F.; Demko, Z. P.; Noodleman, L.; Sharpless, K. B. Why Is Tetrazole Formation by Addition of Azide to Organic Nitriles Catalyzed by zinc(II) Salts? J. Am. Chem. Soc. 2003, 125 (33), 9983-9987.

(18) Gutmann, B.; Roduit, J. P.; Kappe, C. O.; Roberge, D. Synthesis of 5-Substituted $\mathrm{lH}$-Tetrazoles from Nitriles and Hydrazoic Acid by Using a Safe and Scalable High-Temperature Microreactor Approach. Angew. Chem., Int. Ed. 2010, 49 (39), 7101-7105.

(19) Huff, B. E.; Staszak, M. A. A New Method for the Preparation of Tetrazoles from Nitriles Using Trimethylsilylazide/trimethylaluminum. Tetrahedron Lett. 1993, 34 (50), 8011-8014.

(20) Das, B.; Reddy, C. R.; Kumar, D. N.; Krishnaiah, M.; Narender, R. A Simple, Advantageous Synthesis of 5-Substituted $1 \mathrm{H}$-Tetrazoles. Synlett 2010, 2010 (3), 391-394.

(21) Lewis, W. G.; Green, L. G.; Grynszpan, F.; Radić, Z.; Carlier, P. R.; Taylor, P.; Finn, M. G.; Sharpless, K. B. Click Chemistry in Situ: Acetylcholinesterase as a Reaction Vessel for the Selective Assembly of a Femtomolar Inhibitor from an Array of Building Blocks. Angew. Chem., Int. Ed. 2002, 41 (6), 1053-1057.

(22) Wang, Q.; Chan, T. R; Hilgraf, R.; Fokin, V. V.; Sharpless, K. B.; Finn, M. G. Bioconjugation by copper(I)-Catalyzed Azide-Alkyne [3 + 2] Cycloaddition. J. Am. Chem. Soc. 2003, 125 (11), 3192-3193.

(23) Schulze Wischeler, J.; Sun, D.; Sandner, N. U.; Linne, U.; Heine, A.; Koert, U.; Klebe, G. Stereo- and Regioselective Azide/alkyne Cycloadditions in Carbonic Anhydrase II via Tethering, Monitored by Crystallography and Mass Spectrometry. Chem. - Eur. J. 2011, 17 (21), 5842-5851.

(24) Bhardwaj, A.; Kaur, J.; Wuest, M.; Wuest, F. In Situ Click Chemistry Generation of Cyclooxygenase-2 Inhibitors. Nat. Commun. 2017, 8 (1), 1.

(25) Harel, M.; Schalk, I.; Ehret-Sabatier, L.; Bouet, F.; Goeldner, M.; Hirth, C.; Axelsen, P. H.; Silman, I.; Sussman, J. L. Quaternary Ligand Binding to Aromatic Residues in the Active-Site Gorge of Acetylcholinesterase. Proc. Natl. Acad. Sci. U. S. A. 1993, 90 (19), 9031-9035.

(26) Bourne, Y.; Sharpless, K. B.; Taylor, P.; Marchot, P. Steric and Dynamic Parameters Influencing in Situ Cycloadditions to Form Triazole Inhibitors with Crystalline Acetylcholinesterase. J. Am. Chem. Soc. 2016, 138 (5), 1611-1621.

(27) Gulevich, A. V.; Dudnik, A. S.; Chernyak, N.; Gevorgyan, V. Transition Metal-Mediated Synthesis of Monocyclic Aromatic Heterocycles. Chem. Rev. 2013, 113 (5), 3084-3213.

(28) Hashimoto, T.; Maruoka, K. Recent Advances of Catalytic Asymmetric 1,3-Dipolar Cycloadditions. Chem. Rev. 2015, 115, 53665412 .

(29) Frisch, M. J. et al. Gaussian 09, Revision D.01; 2009.

(30) Montgomery, J. A.; Frisch, M. J.; Ochterski, J. W.; Petersson, G. A. A Complete Basis Set Model Chemistry. VI. Use of Density Functional Geometries and Frequencies. J. Chem. Phys. 1999, 110 (6), 2822-2827.

(31) Rappé, A. K. K.; Casewit, C. J. J.; Colwell, K. S. S.; Goddard, W. A., III; Skiff, W. M. UFF, a Full Periodic Table Force Field for Molecular Mechanics and Molecular Dynamics Simulations. J. Am. Chem. Soc. 1992, 114 (25), 10024-10035.
(32) Sousa, S. F.; Fernandes, P. A.; Ramos, M. J. The Carboxylate Shift in Zinc Enzymes: A Computational Study. J. Am. Chem. Soc. 2007, 129 (5), 1378-1385.

(33) Ryde, U. Carboxylate Binding Modes in Zinc Proteins: A Theoretical Study. Biophys. J. 1999, 77 (5), 2777-2787.

(34) Dudev, T.; Lim, C. Tetrahedral vs Octahedral Zinc Complexes with Ligands of Biological Interest: A DFT/CDM Study. J. Am. Chem. Soc. 2000, 122 (45), 11146-11153.

(35) Sousa, S. F.; Fernandes, P. A.; Ramos, M. J. Comparative Assessment of Theoretical Methods for the Determination of Geometrical Properties in Biological Zinc Complexes. J. Phys. Chem. B 2007, 111 (30), 9146-9152.

(36) Liao, R. Z.; Yu, J. G.; Himo, F. Reaction Mechanism of the Dinuclear Zinc Enzyme N-Acyl-L-Homoserine Lactone Hydrolase: A Quantum Chemical Study. Inorg. Chem. 2009, 48 (4), 1442-1448.

(37) Himo, F.; Siegbahn, P. E. Catalytic Mechanism of Glyoxalase I: A Theoretical Study. J. Am. Chem. Soc. 2001, 123 (42), 10280-10289.

(38) Park, H.; Brothers, E. N.; Merz, K. M. Hybrid QM/MM and DIFT Investigations of the Catalytic Mechanism and Inhibition of the Dinuclear Zinc Metallo-Beta-Lactamase CcrA from Bacteroides Fragilis. J. Am. Chem. Soc. 2005, 127 (12), 4232-4241.

(39) Chen, S. L.; Marino, T.; Fang, W. H.; Russo, N.; Himo, F. Peptide Hydrolysis by the Binuclear Zinc Enzyme Aminopeptidase from Aeromonas Proteolytica: A Density Functional Theory Study. J. Phys. Chem. B 2008, 112 (8), 2494-2500.

(40) Cancès, E.; Mennucci, B.; Tomasi, J. A New Integral Equation Formalism for the Polarizable Continuum Model: Theoretical Background and Applications to Isotropic and Anisotropic Dielectrics. J. Chem. Phys. 1997, 107 (8), 3032.

(41) Cossi, M.; Barone, V.; Cammi, R.; Tomasi, J. Ab Initio Study of Solvated Molecules: A New Implementation of the Polarizable Continuum Model. Chem. Phys. Lett. 1996, 255 (4-6), 327-335.

(42) Legault, C. Y. CYLview, 1.0b; Université de Sherbrooke: 2009. http://www.cylview.org (accessed Nov 2, 2017.

(43) Humphrey, W.; Dalke, A.; Schulten, K. VMD: Visual Molecular Dynamics. J. Mol. Graphics 1996, 14 (1), 33-38.

(44) Cantillo, D.; Gutmann, B.; Kappe, C. O. An Experimental and Computational Assessment of Acid-Catalyzed Azide-Nitrile Cycloadditions. J. Org. Chem. 2012, 77 (23), 10882-10890.

(45) Lan, Y.; Zou, L.; Cao, Y.; Houk, K. N. Computational Methods to Calculate Accurate Activation and Reaction Energies of 1,3-Dipolar Cycloadditions of 24 1,3-Dipoles. J. Phys. Chem. A 2011, 115 (47), 13906-13920.

(46) Roh, J.; Vávrová, K.; Hrabálek, A. Synthesis and Functionalization of 5-Substituted Tetrazoles. Eur. J. Org. Chem. 2012, 2012 (31), 6101-6118.

(47) Reetz, M. T. Biocatalysis in Organic Chemistry and Biotechnology: Past, Present, and Future. J. Am. Chem. Soc. 2013, 135 (34), 12480-12496.

(48) Auclair, K.; Sutherland, A.; Kennedy, J.; Witter, D. J.; Van den Heever, J. P.; Hutchinson, C. R.; Vederas, J. C. Lovastatin Nonaketide Synthase Catalyzes an Intramolecular Diels - Alder Reaction of a Substrate Analogue [7]. J. Am. Chem. Soc. 2000, 122, 11519-11520.

(49) Ose, T.; Watanabe, K.; Mie, T.; Honma, M.; Watanabe, H.; Yao, M.; Oikawa, H.; Tanaka, I. Insight into a Natural Diels-Alder Reaction from the Structure of Macrophomate Synthase. Nature 2003, 422 (6928), 185-189.

(50) Ma, S. M.; Li, J. W.-H.; Choi, J. W.; Zhou, H.; Lee, K. K. M.; Moorthie, V. a; Xie, X.; Kealey, J. T.; Da Silva, N. a; Vederas, J. C.; Tang, Y. Complete Reconstitution of a Highly Reducing Iterative Polyketide Synthase. Science (Washington, DC, U. S.) 2009, 326 (5952), 589-592.

(51) Kim, R. R.; Illarionov, B.; Joshi, M.; Cushman, M.; Lee, C. Y.; Eisenreich, W.; Fischer, M.; Bacher, A. Mechanistic Insights on Riboflavin Synthase Inspired by Selective Binding of the 6,7-Dimethyl8-Ribityllumazine Exomethylene Anion. J. Am. Chem. Soc. 2010, 132 (9), 2983-2990.

(52) Chen, Y. L.; Chen, Y. H.; Lin, Y. C.; Tsai, K. C.; Chiu, H. T. Functional Characterization and Substrate Specificity of Spinosyn 
Rhamnosyltransferase by in Vitro Reconstitution of Spinosyn Biosynthetic Enzymes. J. Biol. Chem. 2009, 284 (11), 7352-7363.

(53) Fage, C. D.; Isiorho, E. a; Liu, Y.; Wagner, D. T.; Liu, H.; Keatinge-Clay, A. T. The Structure of SpnF, a Standalone Enzyme That Catalyzes [4 + 2] Cycloaddition. Nat. Chem. Biol. 2015, 11 (4), 256-258.

(54) Byrne, M. J.; Lees, N. R.; Han, L. C.; Van Der Kamp, M. W.; Mulholland, A. J.; Stach, J. E. M.; Willis, C. L.; Race, P. R. The Catalytic Mechanism of a Natural Diels-Alderase Revealed in Molecular Detail. J. Am. Chem. Soc. 2016, 138 (19), 6095-6098.

(55) Linder, M.; Johansson, A. J.; Olsson, T. S. G.; Liebeschuetz, J.; Brinck, T. Computational Design of a Diels-Alderase from a Thermophilic Esterase: The Importance of Dynamics. J. Comput.Aided Mol. Des. 2012, 26 (9), 1079-1095.

(56) Siegel, J. B.; Zanghellini, A.; Lovick, H. M.; Kiss, G.; Lambert, A. R. Computational Design of an Enzyme Catalyst for a Stereoselective Bimolecular Diels-Alder Reaction. Science 2010, 329 (5989), 309-313.

(57) Linder, M.; Johansson, A. J.; Olsson, T. S. G.; Liebeschuetz, J.; Brinck, T. Designing a New Diels-Alderase: A Combinatorial, Semirational Approach Including Dynamic Optimization. J. Chem. Inf. Model. 2011, 51 (8), 1906-1917.

(58) Preiswerk, N.; Beck, T.; Schulz, J. D.; Milovník, P.; Mayer, C.; Siegel, J. B.; Baker, D.; Hilvert, D. Impact of Scaffold Rigidity on the Design and Evolution of an Artificial Diels-Alderase. Proc. Natl. Acad. Sci. U. S. A. 2014, 111 (22), 8013-8018.

(59) Heinisch, T.; Pellizzoni, M.; Dürrenberger, M.; Tinberg, C. E.; Köhler, V.; Klehr, J.; Häussinger, D.; Baker, D.; Ward, T. R. Improving the Catalytic Performance of an Artificial Metalloenzyme by Computational Design. J. Am. Chem. Soc. 2015, 137 (32), 1041410419 .

(60) Key, H. M.; Clark, D. S.; Hartwig, J. F. Generation, Characterization, and Tunable Reactivity of Organometallic Fragments Bound to a Protein Ligand. J. Am. Chem. Soc. 2015, 137 (25), 82618268 .

(61) Okrasa, K.; Kazlauskas, R. J. Manganese-Substituted Carbonic Anhydrase as a New Peroxidase. Chem. - Eur. J. 2006, 12 (6), 15871596.

(62) Jing, Q.; Okrasa, K.; Kazlauskas, R. J. Stereoselective Hydrogenation of Olefins Using Rhodium-Substituted Carbonic Anhydrase - A New Reductase. Chem. - Eur. J. 2009, 15 (6), 13701376.

(63) Piazzetta, P.; Marino, T.; Russo, N.; Salahub, D. R. Direct Hydrogenation of Carbon Dioxide by an Artificial Reductase Obtained by Substituting Rhodium for Zinc in the Carbonic Anhydrase Catalytic Center. A Mechanistic Study. ACS Catal. 2015, 5 (9), 5397-5409.

(64) Jing, Q.; Kazlauskas, R. J. Regioselective Hydroformylation of Styrene Using Rhodium-Substituted Carbonic Anhydrase. ChemCatChem 2010, 2 (8), 953-957.

(65) Yin, D. L. T.; Bernhardt, P.; Morley, K. L.; Jiang, Y.; Cheeseman, J. D.; Purpero, V.; Schrag, J. D.; Kazlauskas, R. J. Switching Catalysis from Hydrolysis to Perhydrolysis in Pseudomonas Fluorescens Esterase. Biochemistry 2010, 49 (9), 1931-1942.

(66) Wilderman, P. R.; Peters, R. J. A Single Residue Switch Converts Abietadiene Synthase into a Pimaradiene Specific Cyclase. J. Am. Chem. Soc. 2007, 129 (51), 15736-15737.

(67) Mukherjee, A.; Rokita, S. E. Single Amino Acid Switch between a Flavin-Dependent Dehalogenase and Nitroreductase. J. Am. Chem. Soc. 2015, 137 (49), 15342-15345.

(68) Williams, S. D.; David, S. S. A Single Engineered Point Mutation in the Adenine Glycosylase MutY Confers Bifunctional glycosylase/AP Lyase Activity. Biochemistry 2000, 39 (33), 10098-10109.

(69) Brondani, P. B.; Dudek, H. M.; Martinoli, C.; Mattevi, A.; Fraaije, M. W. Finding the Switch: Turning a Baeyer-Villiger Monooxygenase into a NADPH Oxidase. J. Am. Chem. Soc. 2014, 136 (49), 16966-16969.

(70) Ess, D. H. Distortion, Interaction, and Conceptual DFT Perspectives of MO4-Alkene ( $\mathrm{M}=\mathrm{Os}, \mathrm{Re}, \mathrm{Tc}, \mathrm{Mn})$ Cycloadditions. J. Org. Chem. 2009, 74 (4), 1498-1508.
(71) Boren, B. C.; Narayan, S.; Rasmussen, L. K.; Zhang, L.; Zhao, H.; Lin, Z.; Jia, G.; Fokin, V. V. Ruthenium-Catalyzed Azide- Alkyne Cycloaddition: Scope and Mechanism. J. Am. Chem. Soc. 2008, 130 (13), 8923-8930.

(72) Nacereddine, A. K.; Layeb, H.; Chafaa, F.; Yahia, W.; Djerourou, A.; Domingo, L. R. A DFT Study of the Role of the Lewis Acid Catalysts in the $[3+2]$ Cycloaddition Reaction of the Electrophilic Nitrone Isomer of Methyl Glyoxylate Oxime with Nucleophilic Cyclopentene. RSC Adv. 2015, 5 (79), 64098-64105.

(73) Arolas, J. L.; Goulas, T.; Pomerantsev, A. P.; Leppla, S. H.; Gomis-Rüth, F. X. Structural Basis for Latency and Function of Immune Inhibitor A Metallopeptidase, a Modulator of the Bacillus Anthracis Secretome. Structure 2016, 24 (1), 25-36.

(74) English, A. C.; Groom, C. R.; Hubbard, R. E. Experimental and Computational Mapping of the Binding Surface of a Crystalline Protein. Protein Eng., Des. Sel. 2001, 14 (1), 47-59.

(75) Wals, K.; Ovaa, H. Unnatural Amino Acid Incorporation in E. Coli: Current and Future Applications in the Design of Therapeutic Proteins. Front. Chem. 2014, 2, 15. 